BISMA

(Bisnis dan Manajemen)
Volume 13, Issue 1, 2020, 47-68

ISSN 2549-7790 (Online)

DOI: 10.26740/bisma.v13n1.p47-68

https://journal.unesa.ac.id/index.php/bisma/index

\title{
Occupational stress management in managerial employees: an analysis of level and source of work stress
}

\author{
Nindria Untarini ${ }^{1 *}$, Sayyida ${ }^{2}$, Sanju Kumar Singh ${ }^{3}$ \\ ${ }^{1,2}$ Universitas Airlangga, Indonesia \\ ${ }^{1}$ Universitas Negeri Surabaya \\ ${ }^{3}$ Tribuvan University, Nepal
}

\begin{abstract}
The sources and effects of stress have been conceptualized from several theoretical and empirical perspectives. This study explores the sources and impacts of job stress in managerial levels in two different countries, namely developing and developed countries. Furthermore, how to deal with and manage job stress for managers are also described. This study reviews the level and source of work stress that researched in academic journals, books, proceedings, reports, and website. After reviewing the literature extensively, it is concluded that managers in each of the two groups of countries experience workplace stress with different work stress sources. Meanwhile, the impact of job stress at the managerial level in the two groups of countries is almost identical. Job stress affects job satisfaction, mental and physical health, high intention to quit the job, and high absenteeism rates. The strategy to ensure employee health and well-being is to provide a stress-free work environment by creating supportive organizational systems, stress auditing, counselling, education and training, and work balance initiatives. It is hoped that the results of this study can be made a role model in managing stress in the work environment, especially at the managerial level, based on the source and impact of work stress so that it can be used as a basis for designing strategies and policies to deal with stress in the workplace. Finally, this study provides guidelines for further research on this topic.
\end{abstract}

Keywords: cause; effect; stress; stress management

Received: July 23, 2020; Accepted: August 31, 2020; Published: October 31, 2020

*Corresponding author

Email: nindria.untarini@feb.unair.ac.id

\section{To cite this document:}

Untarini, N., Sayyida, \& Singh, S. K. (2020). Occupational stress management in managerial employees: an analysis of level and source of work stress. BISMA (Bisnis dan Manajemen), 13(1), 47-68. https://doi.org/10.26740/bisma.v13n1.p47-68.

\section{INTRODUCTION}

Dynamic working conditions and the increasing complexity of the organization's business leaders to higher levels of work stress for employees (Jetha et al., 2017). Job stress has been identified as one of the most significant workplace problems in various countries (Islam et al., 2017). Workplace stress can be a real problem for the organization and its workers. 
Therefore, the best way to prevent work stress is needed to form optimal work organization management. Several reasons are important in understanding the problem of work stress in an organization: (1) job stress has a significant relationship with employee work productivity; (2) job stress is influenced by external and internal factors of the organization so that its existence needs to be realized and understood; (3) understanding the sources of stress and its importance to ensure a sustainable effective organization; (4) leaders and employees have experienced stress even at a very low level; (5) increasing human activity and workload (Chiang et al., 2010).

High job demands and rapid workplace changes result in a higher role and role conflict among managers (O'Reilly \& Tushman, 2011). Nearly 88\% of managers experienced increased stress (De Vibe et al., 2013). Most managers experienced greater job pressure than what can be done (Murphy \& Doherty, 2011). Shahzad et al. (2013) argue that managers who have reached senior level positions usually have a higher level of responsibility for performance, learning, development, growth, and other social support. In the workplace, senior managers must manage cognitive, emotional, and social so that the impact on increased work pressure (Jacobs et al., 2013). Meanwhile, middle managers are specialized in carrying out management functions full of collisions and conflicts that cause stress (Mohr \& Wolfram, 2010).

While carrying out their functions (planning, organizing, staffing, leading, and controlling), middle managers must face upward to the boss, downward to their employees, sideways to their coworkers, and outward to the wider community service users. Middle managers in living their role to do management functions in uneasy organizational climate. They will experience various collisions and conflicts that can cause stress for themselves. Differences in opinion in managing an organization can trigger stress at the manager level if related to their functions and roles.

Several researchers have previously examined the antecedents of job stress among business managers (Malik, 2011; Steinisch et al., 2013). Managers believe that the source and level of work stress are caused by demographics, health, and work pressure (Lu et al., 2011; Mosadeghrad; 2013). However, most studies only focus on the reasons for job stress and its impact on managers work results in some different organizations and countries (Bhagat et al., 2010). The sources and impacts of job stress for managers in different organizational environments are not necessarily the same. Moreover, each country's conditions are also different depending on each country's economic, technological, social, and cultural conditions. Therefore, different stress management methods are needed based on the level of work stress of each manager level. Managers in countries characterized by economic, technological, and social changes experience more mental health problems and job dissatisfaction than managers in developed countries (Shields et al., 2016). Research that examines the source and impact of stress and its management in two different countries has not been conducted. This study explores the sources and impacts of work stress in the organizational environment in two different countries: developing and developed countries in terms of how to manage work stress at the manager level to design strategies and policies in dealing with stress in the work environment. This study will review previous studies about the concept of job stress, types, causes, and consequences of work stress, sources, and impacts of job stress for managers in different organizational environments in two groups of countries, and management of work stress based on the source and impact of job stress. 
This study result is expected to create a role model in managing stress in the work environment, especially at the managerial level, by considering the sources and impacts of work stress. This study is also expected to provide theoretical implications in understanding the problem of stress in the work environment and how to manage work stress as a basis for designing strategies and policies in managing and dealing with stress in the workplace. Finally, this study also provides guidelines for further research on this topic.

\section{METHODS}

This research is a qualitative literature review on the concept of job stress, sources and consequences of work stress, and ways of managing work stress at the managerial level in two groups of countries. Spain, East-European (Bulgaria, Poland, Romania, Estonia, and Ukraine), West-European (Belgium, France, Sweden, and UK), East-Asian (China, Japan, Taiwan, and Hong Kong), and Anglo-Saxon (USA, Canada, and South Africa) are developing countries that examined in this study. Meanwhile, Bangladesh, Pakistan, Malaysia, India, and China are developing countries examined in this study. The information will be obtained that can be used as a basis for designing strategies and policies in managing and coping with stress in the workplace. To identify the relevant studies, this study uses a computerized bibliographic keyword search engine, such as Business Source Elite, ABI/ Inform for business publications, PsycINFO and PSYNDEX for psychology literature, citation index for social science, and internet search with Google Scholar. The literature search conveyed for studies from 1978 to 2019. Based on the search results, 61 articles were obtained, and only 30 articles were selected to be discussed to meet the research objectives.

\section{DISCUSSION}

\section{The Concept of Work Stress}

The word stress is often heard in everyday life both in news, magazines, and other social media. Arnold (1982) argues that stress is any condition that interferes with normal function. According to Beehr \& Newman (1978), stress is a condition that comes from people's interaction with work, which is characterized by changes in a person's self that force them to deviate their normal function. Meanwhile, Selye (1956) defines stress as a non-specific response to each request.

In the scope of this research, the stress in an organizational environment is called job stress. Job stress is defined as a process by which experiences and psychological demands at work result in short-term tension and long-term changes in employees mental and physical health (Ganster \& Rosen, 2013). Research on stress in the work environment has been carried out since the 1970s and 1980s but still focuses on small groups, namely individual work stress. In the 1990s, studies related to stress and its relationship with work began to develop and became a new phenomenon. In recent decades, research on stress has drawn on the personenvironment (P-E) model developed by Khan and French. This model states that adapting to work is the key to success in dealing with stress effectively. If individual abilities and job requirements match both the individual and the organization, it will benefit from the corporation (Edward \& Cooper, 1990). 


\section{Type, Cause, and Consequence of Stress at Workplace}

Managers report that the demands of a challenging job generate positive feelings even though they feel stress. This statement is consistent with the theoretical difference in the stress literature between eustress and distress. Based on its effect on mind and body performance, stress can be categorized into two types (Panigrahi, 2016). (1) Eustress is a reasonable amount of stress that a person can take. This stress creates challenges and feelings of satisfaction or achievement (Selye, 1982). Therefore, this stress has positive side effects. Eustress can create a passion for work and perhaps promote hidden abilities and talents that can lead to success. (2) Distress is an excessive amount of stress. This stress is dangerous and hurts the individual's body and mind, and can cause depression, heart attack, and others.

The pressure and challenges of work at work is something that cannot be avoided. Because the demands in the work environment or stakeholders are growing in line with the times that increasingly require individuals and organizations to be competitive. Someone usually accepts pressure or challenge if the required resources are available sufficiently. However, when the pressure becomes excessive, workers will experience stress, and stress can damage workers health and organizational performance. Workplace factors that were found to be associated with stress and health risks can be categorized as related to job content and their relationship to social and organizational work contexts (Figure 1). It is caused by long hours, work overload, time pressure, difficult or complicated tasks, lack of rest, lack of variation, and poor physical working conditions (e.g. space, temperature, light). Unclear jobs or conflicting roles and boundaries can cause stress, as they relate to responsibility for others. Job development factors, promotions, lack of training, and job insecurity are predictors of current stress.

According to Panigrahi (2016), the causes of stress are divided into two categories based on its source. The two main classifications are internal causes and external causes. Internal causes involve the individual's mindset and way of thinking. These causes come from within the individual and cause stress, which is based on individual perceptions. Even if there are no threats around, a person may feel a threatening person or situation and thus become stressed. External causes include many external factors in an organization that affects individual change and work in the organization, such as job insecurity, erratic working hours, lack of control, managerial style, job overload, and underload, changes in work situations. Smollan (2015) divides three categories of potential stressors: environmental, organizational, and individual. Environmental uncertainty affects the design of organizational structures. Uncertainty also affects the level of stress among employees in an organization. The organizational structure determines the level of differentiation in the organization, rules and regulations, and decisionmaking. Excessive rules and a lack of participation in decision-making that impact employees are potential sources of stress.

In the work context, many instruments have classified sources of stress. Barrick et al. (2012) focused on five key groups: psychological demands, lack of decision latitude, lack of social support, physical demands, and job insecurity. Bogaert et al. (2017) identified six main sources of burnout: workload, lack of control, low rewards, inadequate societal/ social factors), injustice, and inappropriate values. The ASSET instrument contains seven categories of stress sources: work relations, work-life balance, overload, job security, control, resources and communication, salary, and benefits (Johnson et al., 2014). Michie (2002) and McVivar et al. 
(2010) present various stress sources into five general categories, including factors intrinsic to the job, role in the organization, relationships at work, career development, organizational structure, and climate. This category tends to dominate early research in the field of workplace stress.

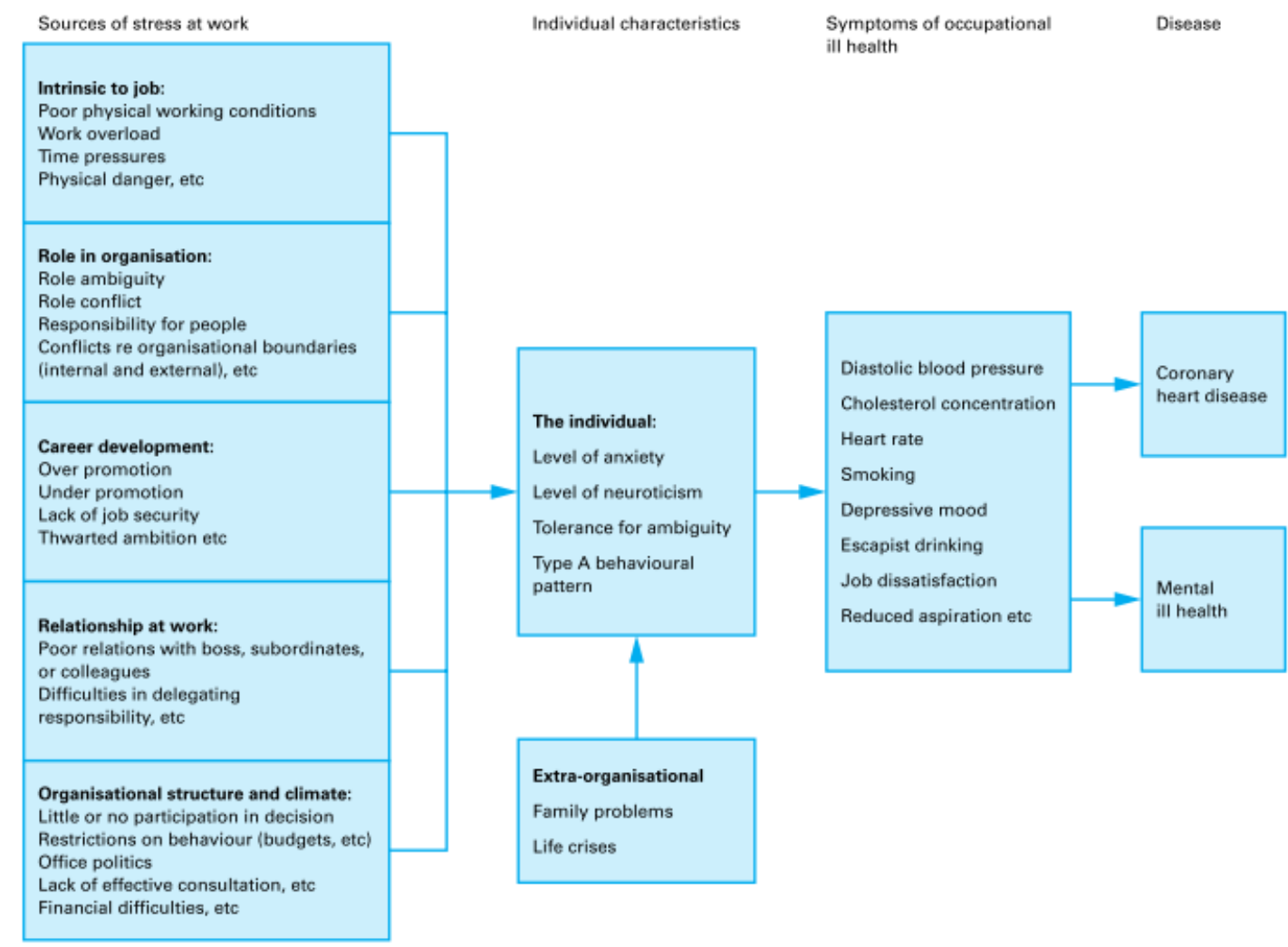

Figure 1. A Model of Stress at Work

In general, stress can lead to physical consequences, psychological problems, and behavioural problems (Panigrahi, 2016). First, the physical consequences. Stress can manifest in various physical observations such as changing human's organ system functions. Stress can cause disruption of body health such as headaches, indigestion, and ringing in the ears. On the other hand, stress creates tension, which results in increased sweating on the body and even disrupts the respiratory system, such as difficulty to breath. Stress also affects the immune system, making it susceptible to infections such as flu. Allergy attacks often occur in stressful conditions due to a sensitive body. Stuttering while speaking, flatulence or burp, and teeth grinding are commonly seen in stressed individuals. Second, psychological problems. Continuous stress causes individual psychology to change. Stress causes a person's selfconfidence to decrease, which can lead to nervousness. Stress causes excessive anxiety, where the individual always worries about the little things. Stressed people always show guilt because they feel less than optimal performance. Stress can also cause insomnia, lead to nightmares for someone, disturbed concentration, make people forget, feel more emotional, feel afraid, and anxious. Prolonged stress causes depression, which hampers the ability to make decisions. Stressed people are more prone to dementia than healthy people. Third, behavioural problems. Stress causes behavioural changes that are immediately visible to stressed individuals, such as 
irritability, frustration, and forgetfulness to remember small details. People were suffering from irregular stress. These people are more confused about making small decisions. They feel lonelier, feel worthless, and show a tendency to commit suicide. People who are stressed are shown to be more likely to behave obsessively or compulsively.

Excessive stress on employees is a dangerous situation for the company because it can lead to employee turnover. Highly stressed employees choose to stay absent from the stressful environment in the organization. Very stressed employees can cause a lack of self-motivation. Several studies have also shown that job stress can negatively affect individuals and the workplace (Ahmed \& Ramzan, 2013). A study shows that a job emphasizing a person tends to have greater job dissatisfaction, increase absenteeism, increase drinking and smoking frequency, increase negative psychological symptoms, and reduce aspirations and self-esteem (Jayashree, 2010). Various studies have shown that workers suffering from stress show a higher reduction in the number of accidents, lower morale, and greater interpersonal conflicts with coworkers and superiors (Burnett \& Pettijohn, 2015; Leung et al., 2012). Data compiled from the U.S. Bureau of Labor Statistics show that highly stressed or anxious employees tend to take more leave (Olson et al., 2011).

\section{Sources of Managerial Work Stressors in Some Countries}

Several pieces of literature about the causes of work stress have been identified in some of the managers in the organizational environment settings in the two groups of countries (Table 1) first, a group of developing countries represented by Pakistan, Bangladesh, Malaysia, India and China. Second, a group of developed countries represented by Spain, West-European (Belgium, France, Sweden, and UK), East-European (Bulgaria, Poland, Romania, Estonia, Romania, and Ukraine), Anglo-Saxon (USA, Canada, and South Africa), and East-Asian (China, Japan, Taiwan, and Hong Kong).

Table 1 shows that the sources of workplace stress for managers between the two groups of countries are not much different. Work stress sources in both developing and developed countries come from intrinsic to the job, role organization, career development, and relationship at work. Meanwhile, the organizational structure and climate factors were not discussed as a source of work stress. Michie (2002) states in the work stress model that the source of work stress comes from intrinsic to the job, role organization, career development, and relationship at work, and organizational structure and climate (Figure 1).

The sources of job stress at the managerial level show different results in some developing and developed countries. In developing countries, sources of work stress range from highest to lowest, respectively. In Pakistan, sources of stress are responsibilities for others, career development, quantitative overload, qualitative overload, and organization role (Shahzad et al., 2013). In Bangladesh, these are career development, other responsibilities, quantitative overload, qualitative overload, and role in the organization (Islam et al., 2017). In Malaysia, these include new technology, working conditions, career development, role in the organization, workloads, video display terminals, risk, and danger (Manshor et al., 2003). In India, these are roles in the organization, organizational system, nature of the job, career development, professional relationship, workload, occupational frustrations, increasing use of technology, change society and culture, work-life balance (Shrivastava, 2015). This condition is different from the source of work stress at the manager level in developed countries. 
Untarini, N., Sayyida, \& Singh. S.K.

Occupational stresss management in managerial employess: an analysis of level and source of work

stress

Table 1. Sources of Job Stress at Managerial Levels in Some Countries

\begin{tabular}{|c|c|c|}
\hline Stressor & $\begin{array}{l}\text { Developing } \\
\text { countries }\end{array}$ & References \\
\hline $\begin{array}{l}\text { New technology, working conditions, career development, } \\
\text { role in the organization, workloads, video display terminals, } \\
\text { risk, and danger }\end{array}$ & Malaysia & Manshor et al. (2003) \\
\hline $\begin{array}{l}\text { Responsibilities for others, career development, quantitative } \\
\text { overload, qualitative overload, and role in the organization }\end{array}$ & $\begin{array}{l}\text { Bangladesh } \\
\text { Pakistan }\end{array}$ & $\begin{array}{l}\text { Atkins et al. (2017) } \\
\text { Shahzad et al. ( 2013) }\end{array}$ \\
\hline $\begin{array}{l}\text { The organizational system, nature of the job, role in the } \\
\text { organization, career development, professional relationship, } \\
\text { workload, occupational frustrations, increasing use of } \\
\text { technology, change society and culture, and work-life } \\
\text { balance }\end{array}$ & India & Shrivastava (2015) \\
\hline $\begin{array}{l}\text { Heavy workload, lack of autonomy, and interpersonal } \\
\text { conflict }\end{array}$ & China & Luo et al. (2011) \\
\hline $\begin{array}{l}\text { Relationship at work, workload, organizational climate, } \\
\text { recognition, managerial responsibilities, manager roles, } \\
\text { home-work balance, and daily hassles }\end{array}$ & Spain & Poelmans et al. (1999) \\
\hline $\begin{array}{l}\text { Workload, relationship at work, organizational climate, } \\
\text { managerial responsibilities, recognition, the manager roles, } \\
\text { home-work balance, and daily hassles }\end{array}$ & $\begin{array}{l}\text { West-European } \\
\text { (Belgium, France, } \\
\text { Sweden, UK, and } \\
\text { German) }\end{array}$ & Poelmans et al. (1999) \\
\hline $\begin{array}{l}\text { Relationship at work, managerial responsibilities, } \\
\text { recognition, organizational climate, workload, daily hassles, } \\
\text { manager roles, and home-work balance }\end{array}$ & $\begin{array}{l}\text { East-European: } \\
\text { (Bulgaria, Poland, } \\
\text { Rumania, } \\
\text { Estonia, and } \\
\text { Ukraine) }\end{array}$ & $\begin{array}{l}\text { (Poelmans et al., 1999) } \\
\text { Stoica (2010) }\end{array}$ \\
\hline $\begin{array}{l}\text { Workload, relationship at work, organizational climate, } \\
\text { managerial responsibility, recognition, manager role, and } \\
\text { home-work balance }\end{array}$ & $\begin{array}{l}\text { Anglo-Saxon: } \\
\text { (USA, Canada, } \\
\text { and South Africa) }\end{array}$ & $\begin{array}{l}\text { Poelmans et al. (1999) } \\
\text { Cavanaugh et al. } \\
\quad(2000)\end{array}$ \\
\hline $\begin{array}{l}\text { Managerial responsibility, relationship at work, } \\
\text { organizational climate, workload, recognition, home-work } \\
\text { balance, and the manager role }\end{array}$ & $\begin{array}{l}\text { East-Asian: } \\
\text { (Japan, Taiwan, } \\
\text { and Hong Kong) }\end{array}$ & $\begin{array}{l}\text { (Siu et al., 1999) } \\
\text { Poelmans et al. (1999) }\end{array}$ \\
\hline
\end{tabular}

According to (Poelmans et al., 1999), the sources of work stress start from the highest to the lowest in developed countries. In Spain, these are relationships at work, workload, organizational climate, recognition, managerial responsibilities, manager roles, home-work balance, and daily hassles. These include workload, relationship at work, organizational climate, managerial responsibilities, recognition, manager roles, home-work balance, and daily hassles in West-European countries. In East-European countries, these are relationships at work, managerial responsibilities, recognition, organizational climate, workload, daily hassles, manager roles, and home-work balance. There are managerial responsibilities in East-Asian countries, relationships at work, organizational climate, workload, recognition, home-work balance, and manager role. In the Anglo-Saxon countries, it is workload, relationship at work, 
organizational climate, managerial responsibility, recognition, manager role, and home-work balance.

This discrepancy pattern may lie in the workload that the managers must bear in each company. Developing countries (Bangladesh, Pakistan, India, Malaysia, and China), which have undergone economic, technological, and social changes, have led to organizational changes and increased employment, resulting in higher job demands. The impact of globalization puts extra pressure on traditional industries in these countries. High job demands and rapid workplace changes have resulted in higher role conflict among managers (Atterwall $\&$ Engqvist, 2016). The individual will experience role conflict when they receive a series of expectations that are not appropriate and must be met simultaneously (Tang \& Chang, 2010). Thus, role conflict is a source of stress experienced by almost all business organizations in developing countries. This is because of situations where managers cannot demonstrate the conflicting demands of colleagues and the organization as a whole.

Likewise, in European, Anglo-Saxon, and East-Asian countries, the workload is an important trigger in work stress (Poelmans et al., 1999). As in Taiwan, managerial roles and hassles appear to be an important source of job stress. The reason for this pattern is that Taiwan adheres to a paternalistic and autocratic culture that governs most organizations in Taiwan, large vs. small, public vs. private (Alon et al., 2011; Sarafis et al., 2016). Autocratic work behaviour leads to a lack of clear and legitimate job role definitions. This often results in workloads and role conflicts. Role ambiguity is the lowest source of stress for managers in Pakistan and Bangladesh. However, most managers experience moderate to high-stress levels because of role ambiguity. Role ambiguity occurs when a person is unsure of what kind of job behaviour to perform in a particular job situation. In this case, when there is a lack of information Atterwall \& Engqvist (2016) related to an employees' role, role ambiguity arises, and this is consistent with the results of research (Holohan, 2018). Nevertheless, in Europen countries, role ambiguity is not the main source of job stress.

Role conflict was found to be the most important source of stress in Bangladeshi business organizations. Likewise, organizations in Pakistan are generally looking for multi-skilled generalists to multitask. This results in a quantitative overload over a qualitative load. Managers in Pakistan are expected to be able to perform tasks that are not by the required resources. When individuals have more than one role to perform simultaneously, they feel overloaded and experience significant stress. According to Makela et al. (2017), quantitative overload results from job achievement demands, which do not match the time available to do the required work. Kuschel (2015) found that qualitative and quantitative overload is responsible for depression, reduced self-esteem, problems with attention, frustration, anxiety, and workplace accidents. This statement is following the results of research by Quick \& Henderson (2016).

The conditions and levels of individual relationships with different workplace employees have also been identified as significant sources of job stress in various organizations (Jacobs et al., 2017). Developing countries (Malaysia, Bangladesh, Pakistan, India) generally have collectivist societies where social harmony, collective growth, and cohesiveness are highly valued and require an informal part of the social setting (Hofstede et al., 2005) so that anything desirable and any confrontation is viewed as a threat to society (Manshor et al., 2003). Meanwhile, in China, the most identified stressors are workers heavy workload, lack of autonomy, 
and interpersonal conflict ( $\mathrm{Lu}$ et al. 2011). While these three stressors may be universal, interpersonal conflict at work has specific relevance to Chinese workers due to the heavy emphasis that Chinese culture places on harmonious relationships in social life, including work.

Managers in Eastern European countries generally feel more pressure emanating from the work environment than managers on other continents. Spain also scores the highest on stress sources from the work environment compared to Western European, Eastern European, and Anglo-Saxon countries (Poelmans et al., 1999). Meanwhile, the study of Hong Kong employees reveals that they have better self-management in managing stress. This is because Hong Kong employees have long been familiar with Western management styles; employees, especially managers, are very concerned about their company's organizational climate (Siu et al., 1999). Managers work in different configurations; change from very diverse people and come from different cultures can ultimately cause job stress. Organizational culture can foster values, attitudes, work styles, create a psychologically different work environment, and form a psychological contract between employers and employees (Sahoo, 2016). This cultural difference makes it difficult for them to adapt to one another. However, we hope that when employees at the managerial level begin to adapt to the organizational culture, this difference can be reduced.

The economic crisis has brought organizations into a reduction in management layers, downsizing, stagnation, and a survival strategy, which will put great pressure on organizational members in career growth and sustainability (Bispinck et al., 2010). When employees experience career advancement difficulties in organizations, they feel career stress (Jalagat, 2017). Working in Bangladesh business organizations is very stressful for managerial-level employees, and managers career development opportunities are becoming rare and difficult (Islam et al., 2017). On the other hand, limited supporting equipment, scarcity of raw materials or resources, excessive organizational expectations of employees to do different jobs always seem to make managers in developing country business organizations such as Malaysia become depressed (Manshor, 2003).

\section{Effect of Managerial Work Stressors in Some Countries}

Workplace stress plays an important role in the physiological and psychological wellbeing of employees. It also affects organizational productivity and performance. Various consequences of stress at work, such as physical problems, mental disorders, emotional imbalances, lifestyle disorders, and behavioural problems, organizational climate disruption. These problems create interpersonal conflicts, decreased productivity, performance dissatisfaction, low organizational commitment, and others. Many kinds of literature on the consequences of job stress is identified in several countries in organizational environments (Table 2). The developing country group is represented by Pakistan, Bangladesh, Malaysia, and India. The group of developed countries represented by Spain, West-European (Belgium, France, Sweden, and UK), East-European (Bulgaria, Poland, Romania, Estonia, Romania, and Ukraine), Anglo-Saxon (USA, Canada, and South Africa), and East-Asian (China, Japan, Taiwan, and Hong Kong).

Table 2 shows that the impact of workplace stress on managers between the two groups of countries is not much different. As a result of work stress, the average employee at the 
managerial level in both developing and developed countries has decreased job satisfaction, decreased mental and physical health, high intention to quit or leave work, and high levels of absenteeism (Islam et al., 2017; Poelmans et al., 1999; Siu et al., 1999). In developing countries, groups such as Malaysia, Bangladesh, Pakistan, and India reported that managers were stressed due to high workloads. Many organizations in Malaysia have reduced the number of working days. However, in most cases, the workload does not change so that it affects the worker's health and ability to cope with stressors, changes in circadian rhythms, and a tendency towards sleep fragility (Manshor et al., 2003). This is consistent with the statement that a job emphasizes individuals tend to have greater job dissatisfaction, increased absenteeism, increased drinking and smoking frequency, increased negative psychological symptoms, and reduced aspiration and self-esteem (Jayashree, 2010).

Table 2. Source of Job Stress at Managerial Levels in Some Countries

\begin{tabular}{|c|c|c|}
\hline Consequences & Country & References \\
\hline Developing Countries & & \\
\hline $\begin{array}{l}\text { Job satisfaction, mental health, physical health, } \\
\text { changes in circadian rhythms, a tendency towards } \\
\text { sleep fragility }\end{array}$ & Malaysia & $\begin{array}{l}\text { Manshor et al. (2003) } \\
\text { Sathasivam et al. (2015) }\end{array}$ \\
\hline Job satisfaction, mental health, physical health & $\begin{array}{l}\text { Bangladesh } \\
\text { Pakistan }\end{array}$ & $\begin{array}{l}\text { Islam et al. (2017) } \\
\text { Shahzad et al. (2013) }\end{array}$ \\
\hline $\begin{array}{l}\text { Job satisfaction, mental health, physical health, } \\
\text { strong sense of commitment and loyalty to } \\
\text { institutions } \\
\text { Developed Countries }\end{array}$ & $\begin{array}{l}\text { India } \\
\text { China }\end{array}$ & $\begin{array}{l}\text { Shrivastava (2015) } \\
\text { Lu et al. (2011) }\end{array}$ \\
\hline $\begin{array}{l}\text { Job satisfaction, mental health, physical health, } \\
\text { achievement/value and growth, the job itself, } \\
\text { organizational design and structure, organizational } \\
\text { processes, personal relationships, mental health, } \\
\text { physical health }\end{array}$ & $\begin{array}{c}\text { Spain } \\
\text { West-European } \\
\text { (Belgium, France, } \\
\text { Sweden, UK, and } \\
\text { German) }\end{array}$ & $\begin{array}{l}\text { Poelmans et al. (1999) } \\
\text { Poelmans et al. (1999) } \\
\text { Johnson et al. (2014) }\end{array}$ \\
\hline Job satisfaction, mental health, physical health & $\begin{array}{l}\text { East-European (Bulgaria, } \\
\text { Poland, Rumania, } \\
\text { Estonia, and Ukraine) }\end{array}$ & Poelmans et al. (1999) \\
\hline $\begin{array}{l}\text { Job satisfaction, mental health, physical health, job } \\
\text { search, voluntary turnover }\end{array}$ & $\begin{array}{l}\text { Anglo-Saxon (USA, } \\
\text { Canada, and South } \\
\text { Africa) }\end{array}$ & Poelmans et al. (1999) \\
\hline $\begin{array}{l}\text { Job satisfaction, mental health, physical health, } \\
\text { absenteeism, intention to quit the job }\end{array}$ & $\begin{array}{c}\text { East-Asian (Japan, } \\
\text { Taiwan, and Hong Kong) }\end{array}$ & $\begin{array}{l}\text { Poelmans et al. (1999) } \\
\text { Siu et al. (1999) }\end{array}$ \\
\hline
\end{tabular}

In a group of developed countries such as Spain, West Europe, East-Europe, East-Asian, and Anglo-Saxon, job stress can decrease job satisfaction, poor mental and physical health (Poelmans et al., 1999). Job stress causes the highest decrease in job satisfaction in AngloSaxon countries. Meanwhile, the impact of job stress on job satisfaction is fewer found in East Eropo, West-Europe, Spain, and East-Asian countries respectively. On the other hand, the reduction in mental health due to the highest work stress occurred in managers in Anglo-Saxon countries, followed by the countries of West Europe, East-Asian, East-Europe, and finally Spain. Spain is the highest country where the consequences of work stress can affect managers physical health in the workplace compared to other developed countries. This is because the Spanish manager reports some of the highest levels of mental tension. Spain also has longer working hours than all other developed countries. This indicates a link between excessive working hours (Nijp et al., 2016). There is a higher work environment pressure in Spain than 
in other countries. Likewise, the combination of work stress and long working hours leads to family and work conflicts, which ultimately impact managers mental health in Spain. The mental strain on managers is very dangerous for the company because it causes concentration, rigid decision making, and reduced ability to think abstractly and associatively.

In Anglo-Saxon countries such as the USA, there is a positive relationship between barriers to job stress on job search behaviour and willingness to turn over voluntarily. The negative relationship between job stress challenges on willingness to look for work assistance and willingness to turn over voluntarily (Steinisch et al., 2013). When faced with challenging job demands such as stressful challenges, managers believe they are coping successfully through personal effort and success in gaining personal improvement and achievement. These stressors can generate feelings of self-confidence, which leads to the ability to solve problems and manage sources of stress (Zhang et al., 2014). Conversely, when faced with hindering job demands, managers believe that they cannot overcome this stressor through personal efforts to reduce their business investment in achieving rewards (Abbas \& Raja, 2019).

In East-Asian countries such as Hong Kong and Taiwan, the source of job stress has a significant and negative correlation with job satisfaction, mental health, and physical health in Hong Kong managers. It is also significantly and positively correlated to absence and intention to quit. However, sources of stress are significantly and positively correlated to Taiwanese managers (Siu et al., 1999). Organizational climate is a strong predictor of the health and strain outcomes of Hong Kong managers. This is because Hong Kong has long been familiar with Western management styles which employees, especially managers, are very concerned about the organizational climate in the company.

In Taiwan, recognition is a predictor of work morale, job satisfaction and quitting intentions. Meanwhile, managerial roles and hassles are important predictors of personal health. This is based on the paternalistic and autocratic culture that governs most organizations in Taiwan, whether they are large, small, public, or private organizations (Hu \& Cheng, 2010). Recognition by superiors determines a person's prospects and status in the organization. Lack of a clear definition of a job role means that a person has to take on duties outside the job description to maintain interpersonal confidentiality or gain recognition from superiors.

\section{Managing Stress at Workplace}

People's ability to mobilize and successfully or unsuccessfully deal with stress factors is called coping, adapting to stress, or stress self-management. The study of interest in coping with stress has increased dramatically in the $80 \mathrm{~s}$. Stress management refers to all means used objectively or subjectively to respond to stressful situations felt by individuals. The anti-stress strategy involves a very high cost but brings great, financially measurable benefits in increasing employee morale. Some organizations have programs designed to help and deal with physical and mental health and stress management. They have prophylactic and therapeutic properties to be effective; the emphasis must continue from treatment to prevention (Stoica, 2010).

Some studies that have examined managing job stress in organizational managers show significant results. Stoica (2010) presents several strategies for preventing and reducing stress at both the organizational and individual levels in Romania's many organizations. Michie 
(2002) attempts to examine the causes of stress in the workplace which is studied empirically and in literature and describes managing stress from an individual and organizational perspective. Meanwhile, Shrivastava (2015) suggests that India's HRM department should focus on measuring and taking steps in managing stress in several managers. Therefore, strategic planning and implementation is a challenge for management.

According to Panigrahi (2016), organizations can manage stress by: (1) reducing long working hour because organization should see that employee hour should be reduced and how to manage time appropriately; (2) teaching employees to do a work-life balance the need for employee training to maintain a work-life balance; (3) use of technology-for performance improvement, organizations need to take advantage of available technology and provide training; (4) good communication must be established between the company and employees and always ask for feedback. Organizations should also strive to follow up on all company and business news and find the best solutions to find and resolve problems related to work stress; (5) organization ensure their employees and the people around them feel safe and not allow unauthorized people to be involved in organizational activities; (6) introduction of retirement plans and pension fund as a guarantee for employees not to worry about retirement; (7) job stability and fear of downsizing-economic crises have resulted in layoffs and downsizing in various organizations. For that, we need guarantees and solutions to minimize the occurrence of work streamlining; (8) workplace diversity-companies must employ all types of work experience from age, gender, and education level.

The problem of job stress has been studied extensively. This is due to the negative impact it has on the organization and employees. Some organizations have programs designed to help physical and mental health workers prevent and deal with stress in the work environment. Stress management is an important part of maintaining good physical and emotional health and healthy relationships with other people. It is important to understand some of the causes of work stress at different managerial levels to design appropriate strategies to prevent and manage them. The best strategy for dealing with the organization's work stress is to redesign the demands, knowledge and abilities, support, and control of an employee's job at the managerial level (Wani, 2013).

Shrivastava (2015) suggests several key points that an organization can take in managing work stress, especially for employees at the managerial level, namely: (1) create a supportive organizational system, implement a decentralized system, create participatory decision-making structures with more upward communication, clarify organizational policies, provide more control and proper job descriptions, and better organizational culture arrangements can help reduce stress experienced by employees; (2) ergonomics and environmental design. The need to repair used equipment and pay attention to physical work conditions, which are in great demand in the technology world, is one strategy to deal with stress at the organizational level and avoid worker frustration; (3) awareness of new technology. The use of computers and software technology is always needed to support organizational performance. It needs proper training and is carried out continuously and regularly for employees; (4) stress counselling such as providing counsellors for employees to help deal with work-related and personal problems; (5) education and training programs. Planning and developing career paths, implementing educational programs that match employee job profiles and lifestyle modification programs at the individual and organizational levels; (6) create organization gathering and fun programs. 
Informal cooperation helps to create personal bonds between various individuals in the organization, thereby contributing to better workplace relationships; (7) stress-auditing. Stressaudit programs need to be carried out at the organizational level to understand the causes of stress and its impact on oneself to make it easier for organizations to design the best strategies to deal with stress; (8) working balance. The company introduced various strategies to help employees achieve work-life balance such as flexible time choices, sharing work, working from home, using telecommuting in fulfilling jobs, and child care support; (9) miscellaneous organizational change.

The workload must match the worker's capabilities and resources. The job design must stimulate and provide broad opportunities for workers to use their skills, clarity on worker roles and responsibilities, improved communication channels, meaningful and timely feedback, and responsibilities answer bigger. Organizational goals must be realistic, have a fair and appropriate distribution of incentives and salary structure, promote job rotation and job enrichment, create an unbiased and safe work environment, have effective recruitment and orientation procedures, reward employees in completing, and ensure social opportunities for interaction between workers. These can all deal with stress at work.

The following shows how to assess and reduce the risks associated with exposure to occupational stress hazards (Michie, 2002), including: (1) hazard identification such as identifying existing stress about conditions during and after work for certain groups of employees, then assessing exposure levels; (2) hazard assessment such as gathering evidence that exposure to stress factors is associated with health problems in the group being assessed or the broader organization. This includes health, including symptoms of general malaise and specific disorders, and organizational and health-related behaviors such as smoking, drinking, and absence of disease; (3) identification of risk factors may occur such as exploring the linkages between exposure to stressors and hazardous measures to identify possible risk factors at the group level and to estimate measures of their significance; (4) explaining the possible mechanisms for exposure to stressors associated with damage to the health of the assessment group or organization; (5) audit existing management control and employee support systems such as identify and assess all management systems to stressor control and work stress experiences and provide support for employees experiencing problems; (6) recommendations regarding residual risk such as carry out management control and existing employee support systems to the correct account, make recommendations about residual risks associated with risk factors in the presence of work stress.

Stress management approach concentrates on changing individuals without changing the source of stress is limited effectiveness and may be counterproductive to identifying sources of stress (Michie, 2002). Based on the results of the previous literature review, this study found that in developing countries, the causes of the highest work stress on managers are career development (Bangladesh), responsibility for others (Pakistan), role in the organization (India), new technology (Malaysia), and interpersonal conflict (China). Many problems can occur throughout managers work-life, especially in career advancement in organizations due to lack of job security, fear of redundancies, retirement, various performance assessments, frustration due to not being promoted, and extreme stress. 
Individuals suffering from stress often show high dissatisfaction, fatigue, job mobility, and poor performance (Lin et al., 2014). Managers in the organization must perform other coworker functions. This is done to maintain broader relationships in the workplace. Some developing countries such as Pakistan have a culture of a collectivity where social harmony, collective growth, and cohesiveness are highly valued. If someone feels unable to refuse his partner's work function, the pressure will arise in him that triggers work stress. This stress can result in disruption of mental and physical health and avoid coworkers with absenteeism from work (Shahzad et al., 2013; Ahmed \& Ramzan, 2013). Role ambiguity occurs when employees at the managerial level do not have a clear picture of job goals, coworker expectations, the job's scope, and responsibilities. Role conflict arises when workers have to choose between competing demands or expectations. Conflict situations can act as a stress factor and disrupt mental and physical health (Ivancevich \& Matteson, 1980). Along with the increasing use of new technology in all fields of work, managers must adapt to these technologies. Lack of skills and expertise in operating technology can lead to stress, which results in increased absenteeism and illness (Shanthi, 2016).

Understanding and identifying some of the causes of work stress at the managerial level is important to make it easier for organizations to design strategies and manage employee work stress at the managerial level. Job stress impacts job dissatisfaction, disruption of mental and physical health, high absenteeism, and intention to quit work. Therefore, the strategy to manage the highest work stress in developing countries is to: (1) miscellaneous organizational change, such as having a fair and appropriate distribution of incentives and salary structures, pension security, promoting job rotation and job enrichment, creating a work environment that is not bias and safe by ensuring job stability and security, respecting employees in completing and ensuring social opportunities for interaction between workers, and clarity of roles and responsibilities of workers; (2) create a supportive organizational system, such as providing more control and appropriate job descriptions for managers; (3) education and training programs, such as planning and developing career paths, implementing educational programs that are in accordance with job profiles and lifestyle modification programs at the individual and organizational level; (4) good communication, such as communication must be well established between the organization and employees capable of employees with employees and always ask for feedback; (5) organizational gathering and fun, such as informal cooperation helps create personal bonds between various individuals in the organization thereby contributing to better relations in the workplace; (6) awareness of new technology, such as users of software technology is always needed to support organizational performance. For that, it needs proper training and is carried out continuously and regularly for employees at the managerial level; (7) ergonomics and environmental design, such as the need for repairs and equipment as well as paying attention to physical working conditions are strategies to deal with stress at the organizational level and avoid worker frustration; (8) audit stress, such as the organization needs to understand and identify what triggers work stress in general and specifically and its impact on the organization and managers themselves.

Second, in developed countries, the causes of work stress for the highest managers are relationship at work (Spain, East-Europe), workload (West-Europe, Anglo-Saxon), and managerial responsibilities (East-Asian). Dealing with superiors, coworkers, and subordinates can dramatically affect how a person feels. Learning to live with other people is one aspect of 
life that can be stressful, resulting in job dissatisfaction, disruption of mental and physical health, and quitting work (Manshor et al., 2003). The imbalance of workload and existing abilities and resources causes stress in the workplace. This condition results in decreased mental and physical health and a high intention to quit work (Poelmans et al., 1999). Employees are given more work than they can reasonably handle, creating excessive work pressure. Workload occurs when employees are given menial, difficult, and tedious tasks to do so that this condition triggers stress, which ultimately shows high dissatisfaction and can lead to aggressive behaviour (Oliver et al., 2010). Some employees at the managerial level may have multiple career families, generally referred to as managerial families, families with at least managerial responsibilities. The pressure from both work and family, which is high, causes managerial stress, which impacts the disruption of mental and physical health, absence, and intention to stop working (Poelmans et al., 1999).

Based on these conditions, organizations can cope with (1) communication, such as building good communication between the organization and employees at the managerial level and there needs to be feedback as a counterweight; (2) create organization gathering, such as organizing events and informal collaborations that can create personal ties and contribute to better relationships between leaders, colleagues, subordinates, and other parties; (3) miscellaneous organizational change, such as workloads that match workers resources, improve communication channels, provide meaningful and timely feedback, and have greater responsibility; (4) teach employees work-life balance, such as the organization introducing various strategies to help employees achieve work-life balance such as flexible time choices, sharing work, working from home, the use of telecommuting in job support, and child care support; (5) stress counseling, such as counselor assistance for employees, is important to help overcome work-related, and personal problems; (6) audit stress, such as audit stress programs, need to be available for employees in identifying sources of stress and designing the best strategies for managing stress. Table 3 explains the summary of how to manage stress based on the stress sources and impacts in the workplace.

The fundamental approach to managing stress must be based on openness, honesty, and integrity. A mutual understanding between staff and managers needs to be created and developed. If not handled properly, organizations and managers must be prepared to deal with absenteeism, illness, injury, and fatigue as a result. Michie (2002) states that most interventions to reduce health risks associated with workplace stress also involve individual and organizational approaches. Organization approach to an individual including psychological, occupational, health, or counselling training and services. It is hoped that this approach can develop skills and self-confidence to change their situation, not to help them adapt and accept stressful situations. The prevention and management of stress in the workplace also require interventions at the organizational level because it is this organization that creates stress. Organizational interventions can range from the structure (e.g. staffing levels, work schedules, and physical environment) to psychological (e.g. social support, control overwork, and participation). An analysis of stress hazards in the workplace should consider all aspects of its design and management and its social and organizational context. Although the priority is prevention, protective measures can be introduced to control risks and reduce hazards. 
Table 3. Managing Stress Based on the Sources and Effects of Stress in the Workplace

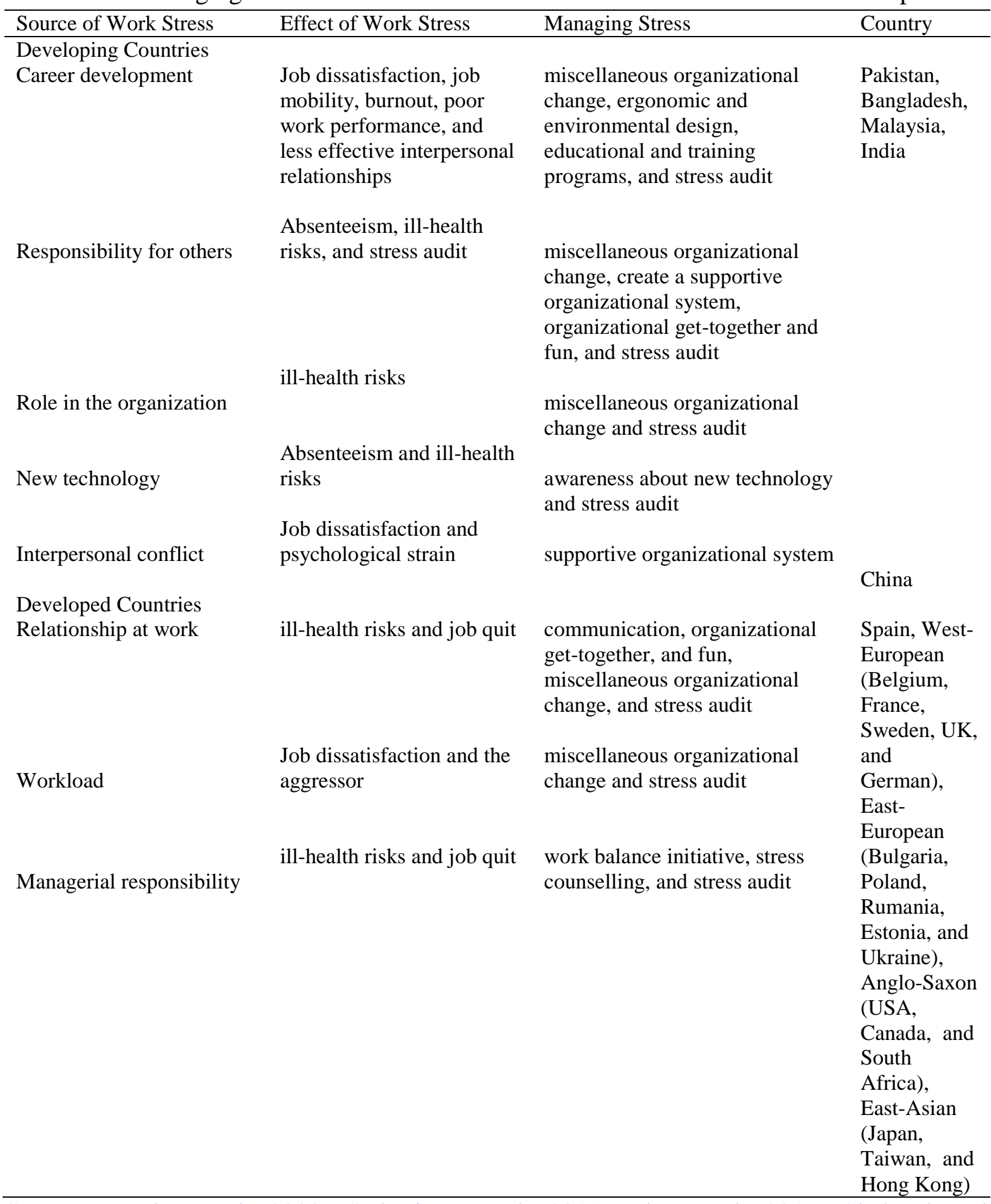

Source: Manshor et al. (2003), Sathasivam et al. (2015), Islam et al. (2017), Shahzad et al. (2013), Poelmans (1999), Stoica \& Buicu (2010), Cavanaugh et al. (2000), and Siu et al. (1999)

\section{CONCLUSION}

Job stress is a real challenge for individuals and organizations. Some studies have well documented the sources of stress in managerial levels, namely role in the organization (role ambiguity, real conflict, and responsibility for people), intrinsic to the job (work overload and poor physical working conditions), career development, and relationship at work. The lowest job stress sources at the managerial level in developing countries that sourced from the role in 
the organization are found in Bangladesh and Pakistan. The highest job stress sources come from responsibility to others (Bangladesh and Pakistan), new technology (Malaysia). In developed countries, the highest sources of work stress are the relationship at work (Spain and East-European), workload (West-European and Anglo-Saxon), managerial responsibilities (East-Asian). Meanwhile, daily hassles (Spain, West-Europe), manager roles (East-Asian), home-work balance (East-Europe and Anglo-Saxon) are the lowest sources of stress at the managerial level of developed countries. Home-work balance and daily hassles are both the lowest contributing sources of work stress.

The phenomenon of stress is a new dimension for human resource management. Good management is characterized by its concern for improving its employees' welfare but also by its concern for improving the health and welfare of its employees. The strategy to ensure the health and well-being of employees is to provide a stress-free work environment. Actions to assess and reduce stress tend to be more difficult in a diverse and challenging job, such as maintaining health. Nevertheless, the effectiveness of organizational interventions to reduce or eliminate sources of stress depends on a good understanding of the stress phenomena experienced by managers. This requires further research on how to detect stress symptoms most effectively when individuals experience initial difficulties so that stress predictions can be known early.

Stress should be viewed as useful information to guide action, not as a weakness in the individual. Several organizations have programs designed to help physical and mental health workers to prevent and deal with problems resulting from work-related stress. Success in managing and preventing stress will depend on the culture of the organization. It is important to build a culture of openness and mutual understanding among managers. Building this culture requires active leadership, role models from the top of the organization, developing, and implementing stress policies. Meanwhile, systems for identifying problems early and reviewing the effectiveness of strategic interventions in managing stress need to be developed. Likewise, related trade unions and occupational health and safety committees also need to be considered. This requires further research on the role of organizational culture as a medium in managing and preventing stress. Besides, active leadership roles, top management initiatives, knowledge, abilities, and organizational support and control can be used as moderation in coping with work stress.

\section{REFERENCES}

Abbas, M. \& Raja, U. (2018). Challenge-Hindrance Stressors and Job Outcomes: The Moderating Role of Conscientiousness. Journal of Business and Psychology, 34(2), 189201. https://doi.org/10.1007/s10869-018-9535-z.

Ahmed, A. \& Ramzan, M. (2013). Effects of Job Stress on Employees Job Performance A Study on Banking Sector of Pakistan. IOSR Journal of Business and Management, 11(6), 61-68. https://doi.org/10.9790/487x-1166168. 
Alon, I., Child, J., Li, S., \& Mcintyre, J. (2011). Globalization of Chinese Firms: Theoretical Universalism or Particularism. Management and Organization Review, 7(2), 191-200. https://doi.org/10.1111/j.1740-8784.2011.00234.x.

Arnold, J. H. (1982). Moderator Variables: A Clarification of Conceptual, Analytic, and Psychometric Issues. Organizational Behavior and Human Performance, 29(2), $143-$ 174. https://doi.org/10.1016/0030-5073(82)90254-9.

Atkins, L., Francis, J., Islam, R., O’Connor, D., Patey, A., Ivers, N., Foy, R., Duncan, E. M., Colquhoun, H., Grimshaw, J. M., Lawton, R., \& Michie, S. (2017) A guide to using the Theoretical Domains Framework of behaviour change to investigate implementation problems. Implementation Science, 12(1), 1-18. https://doi.org/10.1186/s13012-0170605-9.

Atterwall, H. \& Engvist, A. (2016). To Cope with Role Conflict and Work Stress. A middle managerial perspective. Jonkoping University.

Barrick, M. R., Mount, M. K., \& Li, N. (2012). The Theory of Purposeful Work Behavior: The Role of Personality, Higher-Order Goals, and Job Characteristics. The Academy of Management Review, 38(1), 1-44. https://doi.org/10.5465/amr.10.0479.

Beehr, T. A. \& Newman, J. E. (1978). Job stress, employee health, and organizational effectiveness: A facet analysis, model, and literature review. Personnel Psychology, 31(4), 665-699. https://doi.org/10.1111/j.1744-6570.1978.tb02118.x.

Bhagat, R. S., Krishnan, B. C., Nelson, T. A., Leonard, K. M., Ford, D., \& Billing, T. (2010). Organizational Stress, Psychological Strain, and Work Outcomes in Six National Contexts: A Closer Look at the Moderating Influences of Coping Styles and Decision Latitude. Cross Cultural Management: An International Journal, 17(1), 10-29. https://doi.org/10.1108/13527601011016880.

Bispinck, R., Dribbusch, H., \& Öz, F. (2010). Impact of the economic crisis on employees (Issue March). Retrieved August 12, 2020, from https://www.boeckler.de/pdf/p_wsi_report_2_10_english.pdf.

Bogaert, V. P., Peremans, L., Heusden, D. V., Verspuy, M., Kureckova, V., Cruys, Z. V., \& Franck, E. (2017). Predictors of Burnout, Work Engagement and Nurse Reported Job Outcomes and Quality of Care: A Mixed Method Study. BMC Nursing, 16(1), 5. https://doi.org/10.1186/s12912-016-0200-4.

Burnett, M. \& Pettijohn, C. (2015). Investigating the efficacy of mind-body therapies and emotional intelligence on worker stress in an organizational setting: An experimental approach. Journal of Organizational Culture, Communications and Conflict, 19(1), 146158.

Cavanaugh, M. A., Boswell, W. R., Roehling, M. V., \& Boudreau, J. W. (2000). An Empirical Examination Of Self-Reported Work Stress Among U.S. Managers. Journal of Applied Psychology, 85(1) 65-74. https://doi.org/10.1037/0021-9010.85.1.65. 
Chiang, F., Birtch, T. A., \& Kwan, H. K. (2010). The moderating roles of job control and worklife balance practices on employee stress in the hotel and catering industry. International Journal of Hospitality Management, 29(1), 25-32. https://doi.org/10.1016/j.ijhm.2009.04.005.

De Vibe, M., Solhaug, I., Tyssen, R., Friborg, O., Rosenvinge, J. H., Sorlie, T., \& Bjorndal, A. (2013). Mindfulness training for stress management: a randomised controlled study of medical and psychology students. BMC Medical Education, 13(1), 1-11. https://doi.org/10.1186/1472-6920-13-107.

Edwards, J. R., \& Cooper, C. L. (1990). The person-environment fit approach to stress: recurring problems and some suggested solutions. Journal of organizational behavior, 11(4), 293-307. https://doi.org/10.1002/job.4030110405.

Ganster, D. C. \& Rosen, C. C. (2013). Work stress and employee health: A multidisciplinary review. Journal of Management, 39(5), 1085-1122. https://doi.org/10.1177/0149206313475815.

Hofstede, G., Hofstede, G. J., \& Minkov, M. (2005). Culture and Organizations : Software of The Mind. In International Studies of Management \& Organization. New York, Mc Graw Hill.

Holohan, J. (2018). An Exploration of How the Alignment of Business and Information Systems Strategies is Practiced by Information Systems Managers in Ireland's Institutes of Technology. Trinity College Dublin Theses \& Dissertations, Dublin, Ireland. Retrieved August 30, 2019, from http://hdl.handle.net/2262/85037.

Hu, H. H. S. \& Cheng, C. W. (2010). Job stress, coping strategies, and burnout among hotel industry supervisors in Taiwan. The International Journal of Human Resource Management, 21(8), 1337-1350. https://doi.org/10.1080/09585192.2010.483867.

Islam, A., Jantan, A. H., Bashir, A., Masud, S., \& Roy. B. (2017). Work Stress among Managers of Business Organizations in Bangladesh. The International Journal of Business \& Management, 5(10), 16-23.

Ivancevich, J. M. \& Matteson, M. T. (1980). Optimizing Human Resources: A Case for Preventive Health and Stress Management. Organizational Dynamics, 9, 5-25. https://doi.org/10.1016/0090-2616(80)90037-6.

Jacobs, S., Hassell, K., \& Johnson, S. (2013). Managing workplace stress to enhance safer practice in community pharmacy: a scoping study. Retrieved August 12, 2020, from https://pharmacyresearchuk.org/wp-content/uploads/2013/08/Managing-workplacestress-to-enhance-safer-practice-in-community-pharmac-a-scoping-study-executivesummary.pdf.

Jacobs, S., Johnson, S., \& Hassel, K. (2017). Managing workplace stress in community pharmacy organisations: Lessons from a review of the wider stress management and prevention literature. International Journal of Pharmacy Practice, 26(1), 28-38. https://doi.org/10.1111/ijpp.12360. 
Jalagat, R. (2017). Determinants of Job Stress and Its Relationship on Employee Job Performance. American Journal of Management Science and Engineering, 2(1), 1-10. https://doi.org/10.11648/j.ajmse.20170201.11.

Jayashree, R. (2010).Stress Management With Special Reference To public Sector Bank Employees In Chennai. International Journal of Enterprise and Innovation Management Studies (IJEIMS), 1(3), 34-39.

Jetha, A., Kernan, L., \& Kurowski, A. (2017). Conceptualizing the dynamics of workplace stress: a systems-based study of nursing aides. BMC Health Services Research, 17(1), 111. https://doi.org/10.1186/s12913-016-1955-8.

Johnson, S., O'Connor, E.M., Jacobs, S., Hassel, K., \& Ashcroft, D. M. (2014). The relationships among work stress, strain and self-reported errors in UK community pharmacy. Research in Social and Administrative Pharmacy, 10(6), 885-895. https://doi.org/10.1016/j.sapharm.2013.12.003.

Kuschel, K. (2015). Quantitative and qualitative work overload and its double effect on the work-family interface. School of Business and Economics, Universidad del Desarrollo. 27.

Leung, M. Y., Chan, I., \& Yu, J. (2012). Preventing construction worker injury incidents through the management of personal stress and organizational stressors. Accident; analysis and prevention, 48, 156-166. https://doi.org/10.1016/j.aap.2011.03.017.

Lin, W., Ma, J., Wang, L., \& Wang, M. (2015). A double-edged sword: The moderating role of conscientiousness in the relationships between work stressors, psychological strain, and job performance. Journal of Organizational Behavior, 36(1), 94-111. https://doi.org/10.1002/job.1949.

Lu, L., Kao, S. F., Siu, O. L., \& Lu, C. Q. (2011). Work Stress, Chinese Work Values, and Work Well-Being in the Greater China. The Journal of Social Psychology, 151(6), 767783. https://doi.org/10.1080/00224545.2010.538760.

Makela, L., Lamsa, A. M., Heikkinen, S., \& Tanskanen, J. (2017). Work-to-personal-life conflict among dual and single-career expatriates: Is it different for men and women?. Journal of Global Mobility The Home of Expatriate Management Research, 5(3), 304316. https://doi.org/10.1108/jgm-12-2016-0065.

Malik, N. (2011). A study on occupational stress experienced by private and public banks employees in Quetta City. African journal of business management, 5(8), 3063-3070.

Manshor, A. T., Fontaine, R., \& Chong, S. C. (2003). Occupational stress among managers: A Malaysian survey. Journal of Managerial Psychology, 18(6), 622-628. https://doi.org/10.1108/02683940310494412.

McVicar, A., Mun-Giddings, C., \& Seebohm, P. (2013). Workplace stress interventions using participatory action research designs. International Journal of Workplace Health Management, 6(1), 18-37. https://doi.org/10.1108/17538351311312303. 
Occupational stresss management in managerial employess: an analysis of level and source of work

Michie, S. (2002). Causes And Management Ofstress At Work. Occupational \& Environmental Medicine, 59(1), 67-72. http://dx.doi.org/10.1136/oem.59.1.67.

Mohr, G. \& Wolfram, H. J. (2010). Stress Among Managers: The Importance of Dynamic Tasks, Predictability, and Social Support in Unpredictable Times. Journal of Occupational Health Psychology, 15(2), 167-179. https://doi.org/10.1037/a0018892.

Mosadeghrad, A. M. (2013). Occupational Stress and Turnover Intention: Implications for Nursing Management. International Journal of Health Policy and Management, 1(2), 169-176. https://doi.org/10.15171/ijhpm.2013.30.

Murphy, F. \& Doherty, L. (2011). The experience of work life balance for Irish senior managers. An International Journal, 30(4), 252-277. https://doi.org/10.1108/GM-122013-0140.

Nijp, H. H., Beckers, D. G. J., Voorde, K., Geurts, S. A. E., \& Kompier, M. A. J. (2016). Effects of New Ways of Working on Work Hours and Work Location, Health and Job-related Outcomes. Chronobiology International, 33(6), 604-618. https://doi.org/10.3109/07420528.2016.1167731.

Oliver, J. E., Mansell, A., \& Jose, P. E. (2010). A Longitudinal Study of the Role of Negative Affectivity on the Work Stressor-Strain Process. International Journal of Stress Management, 17(1), 56-77. https://doi.org/10.1037/a0017696.

Olson, L. \& Francis, J. P. (2011). Social support and occupational stress among university employees. Graduate Student Journal of Psychology, 13(1), 30-38.

O'Reilly, C. A. \& Tushman, M. L. (2011). Organizational Ambidexterity in Action: How Managers Explore and Exploit. California Management Review, 53(4), 5-22. https://doi.org/10.1017/CBO9781107415324.004.

Panigrahi, A. (2016). Managing Stress at Workplace. Journal of Management Research and Analysis, 3(4), 154-160. https://doi.org/10.18231/2394-2770.2016.0001.

Poelmans, S., Chinchilla, M. N., \& Cardona, P. (1999). An Exploratory Study of Managerial Stress in Spain. In 1st Conference of the Iberoamerican Academy of Management. 1-17.

Quick, J. C. \& Henderson, D. F. (2016). Occupational Stress: Preventing Suffering, Enhancing Well-Being. International Journal of Environmental Research and Public Health, 13(5), 459. https://doi.org/10.3390/ijerph13050459.

Sahoo, S. R. (2016). Management of Stress at Workplace. Type: Double Blind Peer Reviewed International Research, 16(6), 1-9.

Sarafis, P., Rousaki, E., Tsounis, A., Malliarou, M., Lahana, L., Bamidis, P., Niakas, D., \& Papastavrou, E. (2016). The Impact of Occupational Stress on Nurses' Caring Behaviors and Their Health Related Quality of Life. BMC Nursing, 15(1), 1-9. https://doi.org/10.1186/s12912-016-0178-y.

Sathasivam, K.V., A. Malek, M.D.H., \& Abdullah, A.F. (2015). Job Stress among Malaysian 
Managers: The Moderating Role of Coping Methods. International Journal of Social Science Studies, 3(3), 75-86. https://doi.org/10.11114/ijsss.v3i3.742.

Selye, H. (1956). The Stress of Life. New York, USA: McGraw-hill.

Selye, H. (1982). History and Present Status of the Stress Concept En Goldberger, L. y Brenznitz. S.(Eds) Handbook Of Stress. New York: Free Press.

Shahzad, K., Azhar, S., \& Ahmed, F. (2013). A Hidden Threat: Work Stress Among Business Managers in Pakistan. International Journal of Economics and Management, 7(1), 150171.

Shanthi, R. \& Secource, B. (2016). A Study On Stress Management And Coping Strategies With Reference To It Companies. International Journal of Management, 7(2), 636-645.

Shields, G. S., Sazma, M. A., \& Yonelinas, A. P. (2016). The Effects of Acute Stress on Core Executive Functions: A Meta-Analysis and Comparison with Cortisol. Neuroscience and Biobehavioral Reviews, 68, 651-668. https://doi.org/10.1016/j.neubiorev.2016.06.038.

Shrivastava, A. (2015). Organizational Strategies for Managing Occupational Stress in Public Sectors Industries. International Conference on Science, Technology, and Management, 4(1), 664-671.

Siu, O. ling, lu, L., \& Cooper, C. L. (1999). Managerial Stress in Hong Kong and Taiwan: A Comparative Study. Journal of Managerial Psychology, 14(1), 6-25. https://doi.org/10.1108/02683949910254675.

Smollan, R. K. (2015). Causes of Stress Before, During and After Organizational Change: A Qualitative Study. Journal of Organizational Change Management, 28(2), 301-314. https://doi.org/10.1108/JOCM-03-2014-0055.

Steinisch, M., Yusuf, R., Li, J., Rahman, O., Ashraf, H. M., Strümpell, C., Fischer, J. E., \& Loerbroks, A. (2013). Work stress: Its Components and Its Association with SelfReported Health Outcomes in a Garment Factory in Bangladesh-Findings from a CrossSectional Study. Health and Place, 24, 123-130. https://doi.org/10.1016/j.healthplace.2013.09.004.

Stoica, L. M. (2010). Occupational Stress Management. Management in Health, 14(2), 7-9. https://doi.org/10.5233/mih.v14i2.104.

Tang, Y. T. \& Chang, C. H. (2010). Impact of Role Ambiguity and Role Conflict on Employee Creativity. African Journal of Business Management, 4(6), 869-881. https://doi.org/10.1007/s11682-019-00216-2.

Wani, S. K. (2013). Job Stress and It's Impact on Employee Motivation: A Study of A Select Commercial Bank. International Journal of Business and Management Invention, 2(3), $13-18$.

Zhang, Y., Lepine, J. A., Buckman, B. R., \& Wei, F. (2014). It's not Fair . . or Is It? The Role of Justice and Leadership in Explaining Work Stressor-Job Performance Relationships The University of Hong Kong. Academy of Management Journal, 57(3), 675-697. https://doi.org/10.5465/amj.2011.1110. 